\title{
Evaluation of depression and self-esteem in children with monosymptomatic nocturnal enuresis: A controlled trial
}

\author{
Orhan Koca ${ }^{1}$, Mehmet Akyüz ${ }^{1}$, Bilal Karaman ${ }^{1}$, Zeynep Yeşim Özcan ${ }^{2}$, Metin Öztürk ${ }^{1}$, \\ Zülfü Sertkaya $^{1}$, Muhammet Ihsan Karaman ${ }^{1}$ \\ ${ }^{1}$ Haydarpasa Numune Training and Research Hospital, Department of Urology, Istanbul, Turkey; \\ ${ }^{2}$ Haydarpasa Numune Training and Research Hospital, Department of Family Medicine, Istanbul, Turkey.
}

\begin{abstract}
Summary Objectives: Nocturnal enuresis (NE) is very common and is one of the most common causes for patients to be admitted to urology, pediatrics, child psychiatry and child surgery departments. We aimed to investigate the effect on depression and self-esteem of this disorder that can cause problems on person's social development and human relations. Material and methods: 90 patients who were admitted to our clinic with complaints of nocturnal enuresis were enrolled. Investigations to rule out organic causes were performed in this group of patients. Out of them 38 children and adolescents (age range 8-18 years) with primary monosymptomatic nocturnal enuresis (PMNE) agreed to participate in the study In the same period 46 healthy children and adolescents with a similar age range without bed wetting complaint were included in the study as a control group. The age of the family, educational and socioeconomic level were questioned and Piers-Harris Children's Self-Concept Scale (PHCSCS) and Children's Depression Inventory (CDI) forms were filled out. Results: Mean age of the cases (18 females or $47.4 \%$ and 20 males or $52.6 \%$ ) was $10.76 \pm 3.82$ years whereas mean age of controls (26 females or 56.5\% and 20 males or $43.5 \%)$ was $10.89 \pm 3.11$ years. Depression scale was significantly higher $(p=0.001)$ in the case group than in the control group $(10.42 \pm 4.31$ vs $7.09 \pm 4.35)$. In both groups there was no statistically significant difference by age and sex in terms of depression scale $(p>0.05)$. Conclusion: NE is widely seen as in the community and is a source of stresses either for children and for their families. When patients were admitted to physicians for treatment, a multidisciplinary approach should be offered and the necessary psychological support should be provided jointly by child psychiatrists and psychologists.
\end{abstract}

KEY WORDS: Depression; Self-esteem; Nocturnal enuresis.

Submitted 13 June 2014; Accepted 1 August 2014

\section{INTRODUCTION}

Nocturnal enuresis (NE) is very common in the society and is one of the most common causes for patients to be admitted to urology, pediatrics, child psychiatry and child

No conflict of interest declared. surgery departments. NE is recurrent urinary incontinence in children over the 5 years old that is observed during the sleep (1). The prevalence of nocturnal enuresis has been reported as $5.5-16.8 \%(2,3)$. NE is classified as primary and secondary.

NE may cause stress and emotional problems in person and families. On the other hand NE may develop secondary to stress on patients and families (4). However, there are conflicting results as to whether these stressful situations cause psychological problems in enuretic children. Some authors assert that there is no difference of the psychological problems between the normal population and monosymptomatic enuretic children, but some others have argued that NE cause clinical or subclinical psychological problems (5). In a study of bed wetting and behavioral problems, conduct problems and deficits in attention up to age 13 and internalizing problems up to age of 15 have been reported more frequently in children whose bedwetting continue over 10 years of age (6). It may seem that there is a relationship between NE and behavioral problems increasing with age, but cause and effect relationship has not been clearly elucidated (7).

We aimed to investigate the effect on depression and selfesteem of this disorder that can cause problems on person's social development and human relations.

\section{MATERIAL AND METHOD}

Ninety patients who were admitted to our clinic with complaints of nocturnal enuresis were enrolled. Out of them 38 children and adolescents (age range 8-18 years) with primary monosymptomatic nocturnal enuresis (PMNE) agreed to participate in the study and filled out questionnaires. In the same period 46 healthy children and adolescents with a similar age range without bed wetting complaint were included in the study as a control group. Investigations (history, urinalysis, urine culture, urinary tract ultrasonography) were performed in the case group patients to rule out organic causes. Age and educational and socioeconomic levels were questioned in both groups and Piers-Harris Children's Self-Concept Scale (PHCSCS) and Children's Depression Inventory (CDI) forms were filled out. Patients in both groups were classified accord- 
ing to age in 2 groups 8-11 years and > 12 years. NonPMNE wetting bed or patients on any type of treatment were excluded from the study. Patients who missed to fill all or a part of the questionnaire were excluded from the study.

Student t test via SPSS 13 for Windows was used for statistical analyzes. P value $<0.05$ was considered statistically significant.

\section{RESULTS}

Mean age of the cases ( 18 females or $47.4 \%$ and 20 males or $52.6 \%$ ) was $10.76 \pm 3.82$ years whereas mean age of controls (26 females or $56.5 \%$ and 20 males or $43.5 \%$ ) was $10.89 \pm 3.11$ years.

Twenty six patients (68.4\%) out of the case group were 8-11 years of age and $12(31.6 \%)$ were $>12$ years whereas $32(69.6 \%)$ out of the control group were $8-11$ years of age, and 14 (30.4\%) were > 12 years.

There were statistically significant differences between the two groups in self-esteem scale (Table 1).

No statistically significant difference in term of gender was found $(p>0.05)$

In the case group no statistically significant difference of the total score was found by age ( $p>0.05)$, but a statistically significant difference was detected in in term of behavior and comply ( $p=0.022)$. In the control group, no statistically significant difference of the total score was found by age $(P>0.05)$.

Depression scale was significantly higher $(\mathrm{p}=0.001)$ in the case group than in the control group (10.42 \pm 4.31 vs $7.09 \pm 4.35)$. In both groups there was no statistically significant difference by age and sex in terms of depression scale $(p>0.05)$

In both groups, occupation of parents, education and socioeconomic status didn't affect PHCSCS and CDI scores $(p>0.05)$.

\section{Discussion}

NE is fairly common all over the world and this disease averagely affects one in 10 children. Effects on children's social and psychological development are frequently observed. Self-identity and sexual identity are acquired during childhood and adolescence, therefore a number of

\section{Table 1.}

Comparison of the two groups in terms of self-confidence.

\begin{tabular}{|l|c|c|c|}
\hline & Case group N= 38 & Control group N=46 & P value \\
\hline Happiness & $9.26 \pm 3.1$ & $10.71 \pm 1.96$ & 0.012 \\
\hline Anxiety & $7.47 \pm 2.64$ & $9.35 \pm 2.0$ & $<0.001$ \\
\hline Popularity & $7.95 \pm 1.99$ & $9.41 \pm 1.44$ & $<0.001$ \\
\hline Behavior and compliance & $9.97 \pm 3.19$ & $11.28 \pm 2.86$ & 0.051 \\
\hline Physical appearance & $8.05 \pm 1.87$ & $8.22 \pm 1.74$ & 0.677 \\
\hline Mental and school & $5.13 \pm 1.3$ & $5.65 \pm 1.12$ & 0.052 \\
\hline Total & $54.26 \pm 12.98$ & $63.41 \pm 9.14$ & $<0.001$ \\
\hline
\end{tabular}

additional problems like mood disorders are seen with NE. NE is fairly common in our country and causes many negative effects on individuals and families. This condition may cause the fear of being noticed by others, humiliation, anxiety, social withdrawal, high anxiety levels and behavior problems (8).

In a study that investigated how children see enuresis it was reported that bedwetting is the most stressful events after family fights and divorce (9). Adverse effects on mothers have also been described (11). NE has depressive effects on children and their families (10). In our study, a statistically significant difference of depression scores (CDI) was detected between enuretic patients and controls without difference by age, gender, education and socio-economic level. Decreased self-esteem, social adjustment problems in school and with friends and behavior problems have been reported in children with enuresis (12). In our study, a statistically significant difference of self-esteem PHCSCS scores was detected between patients with enuresis and controls with significant difference of sub-titles of happiness, anxiety and popularity. In contrast Hirasing et al reported no significant relationship between nocturnal enuresis and behavioral and emotional problems (13).

Decreased self-esteem was detected in enuretic adults as in children (14). Liu et al. reported that there were more problems with behavior, emotional, and academic achievement in children with NE and observed that they increased with age (15).

Delay of the family to apply to health institutions for therapy increases children self-esteem problems. In our study, only the behavior and adaptation sub-title was significantly different in terms of age whereas age-related differences were not observed by other parameters although this could be explained by insufficient size of the sample. In fact a limitation of our study could be low number of patients from a single center and lack of graduation of the severity of NE.

\section{Conclusions}

In conclusion, NE that is frequently observed in the community is a source of stresses for either children or their families. It should be considered that NE may cause loss of self-confidence and depression in children. Trust should be provided for children and families and training should be given according to treatment planning. When patients were admitted to physicians for treatment, a multidisciplinary approach should be offered and the necessary psychological support should be provided jointly by child psychiatrists and psychologists.

\section{REFERENCES}

1. Nevéus T, von Gontard A, Hoebeke P, et al. The standardization of terminology of lower urinary tract function in children and adolescents: report from the Standardisation Committee of the International Children's Continence Society. J Urol. 2006; 176:314-24. 
2. Bower WF, Moore KH, Shepherd RB, Adams RD. The epidemiology of childhood enuresis in Australia. Br J Urol. 1996; 78:602-6.

3. Kalo BB, Bella H. Enuresis: prevalence and associated factors among primary school children in Saudi Arabia. Acta Paediatr. 1996; 85:1217-22.

4. Chang SS, Ng CF, Wong SN. Behavioural problems in children and parenting stres associated with primary nocturnal enuresis in Hong Kong. Acta Pediatr. 2002; 91:475-9.

5. Butler RJ. Impact of nocturnal enuresis on children and young people. Scand J Urol Nephrol. 2001; 35:169-76.

6. Fergusson DM, Horwood LJ. Nocturnal enuresis and behavioral problems in adolescence: a 15-year longitudinal study. Pediatrics. 1994; 94:662-8.

7. Rocha MM, Costa NJ, Silvares EF. Changes in parents' and selfreports of behavioral problems in Brazilian adolescents after behavioral treatment with urine alarm for nocturnal enuresis. Int Braz J Urol. 2008; 34:749-57.

8. Hägglöf B, Andrén O, Bergström E, et al. Self-esteem in children with nocturnal enuresis and urinary incontinence: improvement of self-esteem after treatment. Eur Urol. 1998; 33 Suppl 3: 16-9.
9. Van Tijen NM, Messer AP, Namdar Z. Perceived stress of nocturnal enuresis in childhood. Br J Urol. 1998; 81 Suppl 3:98-9.

10. Hjalmas K, Arnold T, Bower W, et al. Nocturnal enuresis: an international evidence based management strategy. J Urol. 2004; 171:2545-61.

11. Egemen A, Akil I, Canda E, et al. An evaluation of quality of life of mothers of children with enuresis nocturna. Pediatr Nephrol. 2008; 23:93-8

12. Hägglöf B, Andrén O, Bergström E, et al. Self-esteem before and after treatment in children with nocturnal enuresis and urinary incontinence. Scand J Urol Nephrol. Suppl. 1997; 183:79-82.

13. Hirasing RA, van Leerdam FJ, Bolk-Bennink LB, Bosch JD. Bedwetting and behavioural and/or emotional problems. Acta Paediatr. 1997; 86:1131-4.

14. Theunis M1, Van Hoecke E, Paesbrugge S, et al. Self-image and performance in children with nocturnal enuresis. Eur Urol. 2002; 41:660-7.

15. Liu X, Sun Z, Uchiyama M, et al. Attaining nocturnal urinary control, nocturnal enuresis, and behavioral problems in Chinese children aged 6 through 16 years. J Am Acad Child Adolesc Psychiatry. 2000; 39:1557-64.

\section{Correspondence}

Orhan Koca, MD (Corresponding Author)

drorhankoca@hotmail.com

Mehmet Akyüz, MD

Bilal Karaman, MD

Metin Öztürk, MD

Zülfü Sertkaya, MD

Muhammet Ihsan Karaman, MD

Haydarpasa Numune Training and Research Hospital

Department of Urology

Trbbiye st. no:2 Üsküdar ZIP:34718 Istanbul, Turkey

Zeynep Yeşim Özcan, MD

Haydarpasa Numune Training and Research Hospital

Department of Family Medicine, Istanbul, Turkey 